\title{
GASTROENTERITIS OUTBREAK LINKED TO FOOD HANDLER
}

Peter Yankos

South Eastern Sydney Public Health Unit

Jeremy McAnulty

AIDS/Infectious Diseases Branch

NSW Health Department

I his article reports on an investigation to determine the cause of an outbreak of gastroenteritis in a large Sydney institution employing some 1,100 people, and on control measures that were implemented.

On January 17, 1995 the occupational physician at the institution reported that seven employees were ill with nausea, abdominal cramps, diarrhoea and vomiting, and that 50-60 other employees may also have been ill. His initial inquiries suggested the only common exposure of the seven was that they had eaten together in the institution's cafeteria on January 13.

Foodborne disease outbreaks constitute a significant public health problem in NSW. In 1993, 24 outbreaks involving some 516 cases were reported in the State; this was probably a small fraction of the true number. Viral agents were suspected in five outbreaks and Norwalk-like agents accounted for half of all cases ${ }^{1}$. Factors that contribute to foodborne outbreaks from contaminated food include infected food handlers, inadequate cooking temperatures, improper holding temperatures and contaminated equipment. Most incidents can be easily avoided by adherence to basic rules of food hygiene ${ }^{2}$.

\section{METHODS}

\section{Epidemiological investigation}

The occupational health physician initially conducted telephone inquiries to identify employees who were ill. Subsequently we obtained demographic information from employees, and asked them about their symptoms (including duration), and food consumption on January 13 Cafeteria food handlers were asked about illness before January 13.

We defined a case as an employee who ate at the cafeteria and developed vomiting or diarrhoea and at least one of the following symptoms after January 13: nausea, abdominal cramps, fever, headache, muscle aches or pains. The date was determined on the basis of information on food consumption before onset of symptoms.

We conducted a case-control study in which the controls were employees who ate at the cafeteria and reported no symptoms, identified as a convenience sample. Food consumed and other exposures by cases and controls were compared.

\section{Environmental investigation}

We asked cafeteria managers about food items served on January 13, possible staff illnesses, and food handling and hygiene practices. We inspected the cafeteria to determine food preparation methods, hygiene and storage practices, potential for cross-contamination and temperature abuse. Food handlers were interviewed about food storage, preparation and transportation.

\section{Laboratory investigation}

On January 18 we collected samples remaining from food served on January 13 (including seafood salad, salmon, curried egg, ham, salami, tuna, corned beef, pastrami, egg mayonnaise, milk, cooked chicken pieces, turkey roll,

\section{FIGURE 1}

CASES OF GASTROENTERITIS

AT THE INSTITUTION, JANUARY 1995

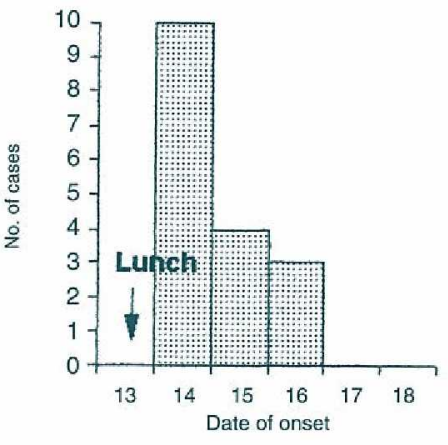

cottage cheese and coleslaw with prawns). The samples were taken to the Division of Analytical Laboratories where they were analysed by standard bacteriological methods looking for faecal coliforms, Escherichia coli, Bacillus cereus, Salmonella and Clostridium perfringens. Stool specimens from cases and food handlers were examined for Salmonella, Shigella, Campylobacter, Yersinia and parasites including Cryptosporidium.

\section{Statistical methods}

The statistical significance of associations between illness and foods consumed was determined using the chi-square test, or the two-tailed Fisher exact test, with a 5 per cent significance level.

\section{RESULTS}

\section{Epidemiological investigation}

We identified 17 cases who reported an onset of illness during the period January 14-16 (Figure 1). For 10 cases, the onset of symptoms was on January 14, while for four cases, symptoms began on January 15 , and for three, on January 16. There were no new cases after January 16. Ten (58 per cent) were males and median age was 34 years (range 19-58 years). The cases were employed in a variety of work areas within the institution. Symptoms included vomiting (reported by 88 per cent), diarrhoea ( 77 per cent), nausea ( 82 per cent), fever ( 65 per cent) and abdominal cramps (53 per cent).

In the case-control study, age and sex distributions of cases and controls were similar. Among the 17 cases and 13 controls, no single food item was associated with the illness. However, 14 of the 17 cases ( 82 per cent) consumed sandwiches, compared with 5 of the 13 controls (38 per cent) (odds ratio $7.5, \mathrm{p}<0.05$ ) (Table 4 ).

The mean period from consumption of sandwiches on January 13 to onset of first symptom was 48 hours (range 30-73 hours, median 47 hours).

\section{Environmental investigation}

The cafeteria was serviced by a catering company.

Employees could also bring food from home or other shops at least three kilometres away. 


\section{Gastroenteritis outbreak}

Continued from page 101

One of the food handlers in the cafeteria reported an illness characterised by abdominal cramps, vomiting and diarrhoea beginning on January 12. Despite this illness the food handler was able to continue working in the food preparation area on the morning of January 13. Two other food handlers reported developing similar symptoms on January 14 and 15.

Storage temperatures of some of the potentially high-risk fillings in the sandwich bar were above the recommended temperature of $5{ }^{\circ} \mathrm{C}$ (ham and salami $20^{\circ} \mathrm{C}$, chicken $11^{\circ} \mathrm{C}$ ). Inspection of the cool-rooms revealed that towels were used to wrap different types of cold cuts. The hand-washing basin at the time of inspection was being used to cool boiled eggs.

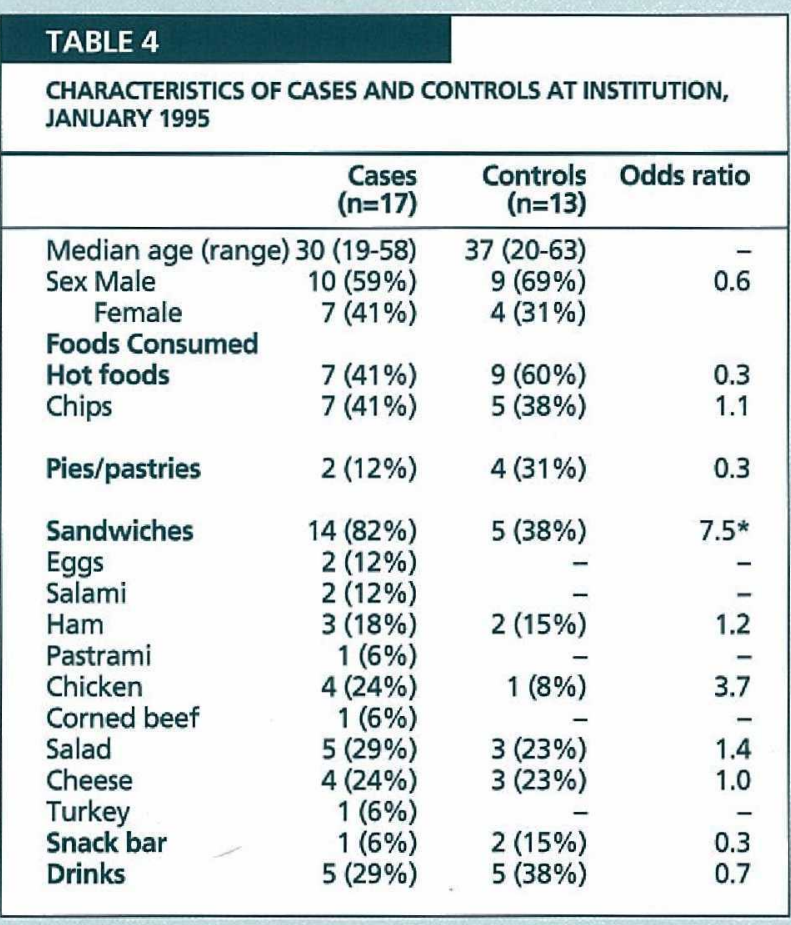

\section{Laboratory investigation}

Microbiological examination of the food samples showed evidence of faecal coliform contamination in the corned beef, ham, seafood salad, salmon, turkey roll and chicken pieces. Escherichia coli was present in the chicken pieces, ham and corned beef. Salmonella ohio was detected in the corned beef (Table 5).

Stool specimens from four ill cafeteria staff (collected within 72 hours of onset) were negative for bacteria and parasites.

\section{CONTROL MEASURES}

On learning of the possible link to the cafeteria, the catering company voluntarily closed the cafeteria. Food items were removed from sale and food preparation areas disinfected. IIl food handlers were removed from kitchen duties until completely free of symptoms and stool samples were clear.

We provided advice to the food handlers and management on food safety and hygiene. They were advised to ensure that storage temperatures of potentially high-risk fillings in the sandwich bar were kept below $5^{\circ} \mathrm{C}$, and to modify foodhandling practices (methods of storing and wrapping food items). They were also educated on the need for personal hygiene to minimise the possibility of contamination spread (use of hand-washing basin and sinks).

\section{DISCUSSION}

The symptoms, incubation period and absence of other pathogens in human specimens suggest this outbreak was caused by a Norwalk-like virus passed from an infected food handler to sandwiches. The laboratory finding of faecal contamination of a number of samples supports the epidemiological finding that consumption of a number of sandwich items led to illness. The isolation of salmonella in one corned beef sample may have been coincidental.

Frequently two or more factors act together to cause contamination and promote survival of pathogens. Examples include contamination of food by infected food handlers and cross-contamination of food from uncooked food items.

\section{TABLE 5}

MICROBIOLOGICAL EXAMINATION OF THE FOOD SAMPLES (JANUARY 18, 1995)

\begin{tabular}{|lrrrrrr}
\hline Sample type & Seafood salad & Salmon & Ham & Corned beef & Cooked chicken \\
\hline Standard Plate & & & & & Turkey roll \\
Count/g & $4.5 \times 10^{5}$ & $2.0 \times 10^{6}$ & $3.2 \times 10^{8}$ & $8.4 \times 10^{7}$ & $1.0 \times 10^{9}$ \\
Salmonella & $\mathrm{ND}$ & $\mathrm{ND}$ & $\mathrm{ND}$ & $\mathrm{Detected}$ & $2.5 \times 10^{7}$ \\
Faecal coliforms/g & 9 & 4 & 23 & $4.3 \times 10^{2}$ & $\mathrm{ND}$ \\
E.coli/g & $<3$ & $<3$ & 23 & $1.5 \times 10^{2}$ & 93 \\
Clostridium perfringens/g & & $<50$ & $<50$ & $<$ & $<50$ \\
\hline
\end{tabular}




\section{Controlling emerging diseases}

\section{$\checkmark$ Continued from page 97}

Folk medicines - Many home remedies, particularly popular in some communities, may contain lead. Examples that may contain as much as 75 per cent lead by weight include greta and azarcon remedies, used in Latin American communities for stomach ailments ('empacho'), or 'pay-looah' used similarly in South-east Asian communities.

Housewares - Lead may leach from improperly fired pottery and ceramic dishes, most commonly of overseas manufacture. Lead is also found in expensive crystal; surprisingly high concentrations are found in liquor and other beverages stored in crystal decanters. Pewter houseware is also a potential source of lead exposure.

Soil and dust - Soil around heavily travelled roads or industries that use lead (e.g. smelting, mining or lead factories) can be highly contaminated. Soil around older lead-painted buildings can also have high levels of lead.

Other sources - Contaminated illicit methamphetamine and derivative drugs have been reported, occasionally resulting in common-source outbreaks of lead intoxication among injection drug users. Imported canned foods may be contaminated if lead-containing solders were improperly used to seal the can.

'Secondary transmission' - While lead intoxication is obviously not a communicable disease, household contacts of people with occupational, vocational, or other exposures may be exposed to lead dust or other compounds brought home by the affected individual, e.g. on clothing. People who are occupationally exposed to lead should shower and change clothes before leaving the workplace.

Purpose of reporting and surveillance is to:

- assess the magnitude of the lead exposure problem in NSW;

identify and control the sources of lead exposure for people with elevated blood lead levels (EBLLs), and to identify and evaluate others who may be at risk from those sources; and ensure that people with lead intoxication receive proper medical management, including follow-up until their concentration of blood lead is brought down to acceptable levels.

All individuals with EBLLs $\geq 0.72 \mu \mathrm{Mol} / 1$ ( $15 \mu \mathrm{g} / \mathrm{dl}$ ) must be reported by labs to the PHU by telephone or mail.

\section{Case follow-up}

The single most important factor in managing childhood lead poisoning is reducing the child's exposure to lead. Working with the patient's medical practitioner, PHU staff will contact the patient or family to provide information about lead poisoning and referral for therapy, assess the risk to other potentially exposed people and provide counselling about how to reduce exposure. Occupationally-associated cases will be referred to Workcover for follow-up.

\section{ACKNOWLEDGMENT}

We thank the Oregon Health Division at the Centre for Disease Prevention and Epidemiology for assistance.

\section{Gastroenteritis outbreak}

\section{$\checkmark$ Continued from page 102}

ingredients ${ }^{3}$. Since the same factors can potentially promote outbreaks caused by a variety of organisms, gastroenteritis outbreaks involving multiple organisms are not unexpected.

The major contributing factors in the outbreak described here were as follows:

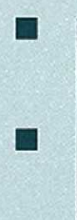

a staff member suffering from gastroenteritis continued to be involved in food handling while ill, thus spreading the organism; and poor personal hygiene practices among food handlers (as evidenced by findings of faecal coliforms and E.coli in food samples).

Use of a hand-washing basin to store food may have also increased the likelihood of contamination.

This case-control study was limited in its ability to detect differences in exposures by the relatively small numbers of cases and controls. A further limiting factor of the investigation was that food samples were taken several days after contaminated foods were consumed. Despite the absence of viral testing, the epidemiology, clinical and microbiological features of the outbreak points to a viral agent as a likely cause.

Food poisoning is usually an avoidable disease. In most cases it can be prevented simply by applying established hygienic principles in the manufacture, preparation, handling, storage and serving of food. Important measures to reduce the incidence of foodborne disease are:

口 training of food service personnel in food hygiene; a application of appropriate food hygiene legislation; and removal of $i l l$ workers from food-handling duties while contagious.

\section{ACKNOWLEDGMENTS}

The authors thank the microbiology section of the NSW Health Department's Division of Analytical Laboratories, staff of the former South Sydney Public Health Unit, and Miss Angela Wong, Food Inspector, South Eastern Sydney Public Health Unit, for her assistance with many aspects of this investigation.

1. Infectious Disease Notifications 1993. NSW Public Health Bulletin $1995 ; 6(\mathrm{~S}-1): 14$

2. Centers for Disease Control. Foodborne Disease Outbreaks: 5-Year Summary, 1983-1987. MMWR 1990; 39(SS-1):39-59.

3. Davey GR. Food Poisoning in New South Wales:1977-84. Food Technology Australia 1985; 37(10):453-56. 